\title{
Cultivo do abacaxizeiro em função do parcelamento da adubação potássica de
}

\section{cobertura}

\author{
Cultivation of pineapple as a function of the splitting of top-dressing potassium fertilization \\ Cultivo de piña en función de la división de la fertilización con potasio del aderezo
}

Recebido: 02/06/2021 | Revisado: 08/06/2021 | Aceito: 14/06/2021 | Publicado: 27/06/2021

Duilhio da Silva Loures

ORCID: https://orcid.org/0000-0003-1804-7053 Universidade do Estado de Mato Grosso, Brasil E-mail: duilhioloures1@ hotmail.com

Oscar Mitsuo Yamashita ORCID: https://orcid.org/0000-0001-6715-626X Universidade do Estado de Mato Grosso, Brasil E-mail: yama@unemat.br

Marco Antonio Camillo de Carvalho ORCID: https://orcid.org/0000-0003-4966-1013 Universidade do Estado de Mato Grosso, Brasil E-mail: marcocarvalho@unemat.br Paulo Sergio Koga ORCID: https://orcid.org/0000-0003-0369-5787 Universidade do Estado de Mato Grosso, Brasil E-mail: paulokoga@unemat.br

Ostenildo Ribeiro Campos

ORCID: https://orcid.org/0000-0002-5434-1463 Universidade do Estado de Mato Grosso, Brasil E-mail: campos@unemat.br

João Aguilar Massaroto

ORCID: https://orcid.org/0000-0002-1845-4225 Universidade do Estado de Mato Grosso, Brasil E-mail: massaroto@unemat.br

Kelte Resende Arantes

ORCID: https://orcid.org/0000-0003-4007-4744 Universidade Federal de Mato Grosso, Brasil E-mail: kelte@unemat.br

Ricardo Adriano Felito

ORCID: https://orcid.org/0000-0002-8323-4720 Instituto Federal de Mato Grosso, Brasil E-mail: ricardofelito@hotmail.com

Wagner Gervazio

ORCID: https://orcid.org/0000-0002-3359-2730

Universidade do Estado de Mato Grosso, Brasil

E-mail: wagnergervazioengagro@gmail.com

Adriano Maltezo da Rocha

ORCID: https://orcid.org/0000-0002-0032-0034 Universidade Estadual Júlio de Mesquita Filho, Brasil E-mail: admr.maltezo@hotmail.com

Aureane Cristina Teixeira Ferreira Cândido

ORCID: https://orcid.org/0000-0001-7540-1325

Universidade Federal do Oeste do Pará, Brasil E-mail: aurianeferreira@hotmail.com

\section{Resumo}

$\mathrm{Na}$ agricultura, a fruticultura constitui-se num dos campos de grande importância. O abacaxi está entre as espécies frutícolas tropicais em importância econômica e social mais desenvolvida nos países de clima tropical e subtropical. O Brasil é um dos maiores produtores mundiais de abacaxi. Assim necessita-se de mais pesquisas sobre esta fruta, para escolher a melhor dose de cobertura potássica e indução floral, e consequentemente maximizar a produção, dando a possibilidade de escalonar a colheita. O objetivo do trabalho foi verificar o desenvolvimento do abacaxizeiro cultivar Pérola, em diferentes doses de adubações de potássio em cobertura, e avaliando seus efeitos sobre a produção de fruto em lavoura de sequeiro no município de Alta Floresta-MT. O delineamento experimental foi de blocos casualizados no esquema fatorial $3 \times 2$, com 24 tratamentos, constituídos por 3 doses de potássio (0, 10 e 20 g planta-1), 2 intervalos de adubação (30 e 60 dias). Nas condições do presente trabalho, pode-se concluir que: doses de até 10 
gramas por planta de potássio aumentam o peso de frutos, independentemente da presença de coroa nestes; maiores valores de diâmetro de fruto são obtidos com adubação potássica de até 20 gramas por planta aos 60 dias e até 10 gramas por planta aos 30 dias após a indução floral; o aumento na dose de potássio melhorar coloração de frutos e aumenta o teor de sólidos solúveis destes.

Palavras-chave: Ananas comosus; Pérola; Produtividade; Cloreto de potássio.

\begin{abstract}
In agriculture, horticulture constitutes a field of great importance. The pineapple is among the tropical fruit species in economic and social importance in most developed countries of tropical and subtropical climate. Brazil is one of the largest producers of pineapple. So is need for more research on this fruit, to choose the best dose of potassium coverage and floral induction, and therefore maximize production, giving the possibility of spreading the harvest. The objective of this study was to investigate the development of Perola pineapple at different doses of potassium fertilizers in coverage, and evaluating their effects on fruit yield in dryland farming in the municipality of Alta Floresta, MT. The experimental design was a randomized block design in $3 \times 2$ factorial design, with 24 treatments, consisting of 3 doses of potassium ( 0,10 and $20 \mathrm{~g}$ plant-1), 2 fertilization intervals (30 and 60). Under the conditions of this study, it was concluded that the best dose of potassium chloride in coverage for Perola pineapple, fruit color variables, average fruit diameter and average fruit weight is $120 \mathrm{~g}$ per plant. The range more suitable for the application of $\mathrm{K}$ was 60 days.
\end{abstract}

Keywords: Ananas comosus; Fruit; Productivity; Potassium cloride.

\title{
Resumen
}

En agricultura, la fruticultura es uno de los campos más importantes. La piña se encuentra entre las especies de frutas tropicales más desarrolladas en importancia económica y social en países con clima tropical y subtropical. Brasil es uno de los mayores productores de piña del mundo. Por lo tanto, se necesita más investigación sobre esta fruta, para elegir la mejor dosis de cobertura de potasio e inducción floral, y en consecuencia maximizar la producción, dando la posibilidad de escalonar la cosecha. El objetivo del trabajo fue verificar el desarrollo del cultivar de piña Pérola, en diferentes dosis de fertilizantes potásicos en cobertura, y evaluar sus efectos en la producción de frutos en cultivos de secano en el municipio de Alta Floresta-MT. El diseño experimental fue de bloques al azar en un esquema factorial 3 x 2, con 24 tratamientos, consistente en 3 dosis de potasio (0, 10 y 20 g planta-1), 2 intervalos de fertilización (30 y 60 días). En las condiciones del presente trabajo, se puede concluir que: dosis de hasta 10 gramos de potasio por planta aumentan el peso de los frutos, independientemente de la presencia de corona en ellos; se obtienen mayores valores de diámetro de fruto con fertilización con potasio de hasta 20 gramos por planta a los 60 días y hasta 10 gramos por planta a los 30 días después de la inducción floral; el aumento de la dosis de potasio mejora el color de los frutos y aumenta el contenido de sólidos solubles de estos.

Palabras clave: Ananas comosus; Perla; Productividad; Cloruro de potasio.

\section{Introdução}

O abacaxizeiro é uma espécie tropical de grande importância econômica para o Brasil, especialmente por sua grande aceitabilidade tanto no mercado interno como externo e, durante a produção do fruto, inúmeros são os segmentos que atrelados à essa atividade, desde a geração de empregos no campo e os setores que tratam do seu processamento e comercialização. (Guimarães et al., 2017).

O Brasil é um dos maiores produtores mundiais de abacaxi, destacando-se o principal da América do Sul, sendo cultivado em todas as unidades da federação, especialmente a cultivar "Pérola", que é a mais cultivada e com grande aceitação no mercado consumidor (Yamashita et al., 2017; Kist et al., 2018).

A cultura do abacaxi destaca-se como uma das alternativas de exploração do potencial frutícola em diversos municípios no interior do Brasil, onde o clima permita esta exploração agrícola (Santos et al., 2017), como o norte do estado do Mato Grosso. Essa cultura pode colaborar para a viabilização da prática de cultivos na agricultura familiar, permitindo o uso da mão de obra da propriedade rural em todas as etapas desde o plantio até a pós-colheita, comercialização, distribuição e industrialização desses frutos in natura (Guimarães et al., 2017; Cunha et al., 2021).

Embora com pontos positivos, há necessidade de pesquisa que permitam a esses produtores conduzirem lavouras produtivas e sadias, com frutos de qualidade e com alto rendimento, principalmente em épocas de escassez do produto no mercado, garantindo a sua continuidade e com bons resultados financeiros. Alguns fatores ambientais adversos, problemas 
fitossanitários, práticas culturais inadequadas, épocas de plantio, adubação e indução floral podem contribuir para uma possível queda de produtividade (Conceição et al., 2016).

Dada a importância econômica da cultura, estudos sobre adubação durante seu desenvolvimento tornam-se importantes (Guarçoni \& Ventura, 2011; Silva et al., 2015). Os nutrientes mais exigidos pela cultura do abacaxizeiro são potássio, nitrogênio e cálcio (Guarçoni \& Ventura, 2011). Quanto à exigência de nutrientes, calcula-se que haja extração de aproximadamente $350 \mathrm{~kg} \mathrm{ha}^{-1}$ de N, $30 \mathrm{~kg} \mathrm{ha}^{-1}$ de P e $500 \mathrm{~kg} \mathrm{ha}^{-1}$ de K, em cultivos com população de 50.000 plantas ha-1 (Maeda, 2005). Além disso, o ciclo de produção da cultura que pode superar os 20 meses a campo, fazendo com que seja necessário o parcelamento da aplicação de fertilizantes (Ribeiro, 2016). Assim, o parcelamento no fornecimento de $\mathrm{N}$ e $\mathrm{K}$ permite que haja a disponibilização desses nutrientes durante os momentos críticos da cultura, suprindo as exigências nutricionais da planta. Desta maneira, é possível minimizar perdas por lixiviação e melhorar a eficiência das fertilizações (Cunha et al., 2021).

Sabe-se que os solos da Amazônia, em geral, apresentam baixa fertilidade natural necessitando-se, em cultivos nessa região, a aplicação de quantidades suficientes de nutrientes para o pleno desenvolvimento das plantas e consequentemente, elevação da qualidade dos frutos produzidos (Veloso et al., 2001).

Além disso, a indução floral, prática comum no cultivo do abacaxizeiro, pode permitir padronizar a formação dos frutos, auxiliando no escalonamento da maturação dos frutos (Yamashita et al., 2017). Entretanto, o estudo do período mais apropriado para o parcelamento da aplicação de fertilizante juntamente com a época de indução floral é pouco estudada e merece atenção, especialmente em localidades onde o cultivo do abacaxizeiro é bem incipiente, como a região norte do estado de Mato Grosso.

O trabalho teve como objetivo estudar o desenvolvimento do abacaxizeiro cultivar Pérola, em função de diferentes doses de adubação potássica, aplicadas em diferentes intervalos de tempo, avaliando seus efeitos sobre a produção de frutos no município de Alta Floresta-MT.

\section{Metodologia}

Trata-se de uma pesquisa quantitativa (Pereira et al., 2018.). O experimento foi instalado em 2012 numa área experimental localizada no município de Alta Floresta, região norte do estado de Mato Grosso, Amazônia meridional, apresentando como coordenadas geográficas $09^{\circ} 55^{\prime} 12^{\prime \prime}$ latitude Sul, 56¹3’36" longitude, Oeste Gr., com altitude de 290 metros. A região é caracterizada por clima tropical chuvoso (tipo Am), com duas estações climáticas de chuva seca bem definidas, apresentando precipitação anual de até $3.100 \mathrm{~mm}$, sendo a média de $2.950 \mathrm{~mm}$ (Alvares et al., 2014).

O solo do local foi classificado como Latossolo Vermelho-Amarelo distrófico (LVAd. A precipitação média anual é de $2.700 \mathrm{~mm}$ e a temperatura média anual de $24{ }^{\circ} \mathrm{C}$. As características físicas e químicas do solo da área experimental estão apresentadas na Tabela 1. 
Tabela 1 - Caracterização química e física do solo da área experimental.

\begin{tabular}{|c|c|c|c|c|c|c|c|c|c|c|c|c|}
\hline \multicolumn{2}{|c|}{$\mathrm{pH}$} & $\mathrm{P}$ & $\mathrm{K}$ & $\begin{array}{l}\mathrm{Ca}+ \\
\mathrm{Mg}\end{array}$ & $\mathrm{Ca}$ & $\mathrm{Mg}$ & $\mathrm{Al}$ & $\mathrm{H}$ & \multirow{3}{*}{$\begin{array}{c}\text { M. O. } \\
\text { d dm }^{-3} \\
19,21 \\
\end{array}$} & Areia & \multirow{2}{*}{$\begin{array}{l}\text { Silte } \\
\mathrm{g} \mathrm{kg}^{-1}\end{array}$} & \multirow[t]{2}{*}{ Argila } \\
\hline Água & $\mathrm{CaCl}_{2}$ & \multicolumn{2}{|c|}{$\mathrm{mg} \mathrm{dm}^{-3}$} & \multicolumn{5}{|c|}{$\mathrm{cmol}_{\mathrm{c}} \mathrm{dm}^{-3}$} & & & & \\
\hline 4,2 & 4,1 & 5,68 & 58 & 0,76 & 0,52 & 0,24 & 0,40 & 3,60 & & 582 & 63 & 355 \\
\hline \multicolumn{2}{|c|}{$\begin{array}{c}\text { Soma de } \\
\text { Bases (S) }\end{array}$} & СТC & Sat. p & Bases & \multicolumn{3}{|c|}{ Relações } & \multicolumn{4}{|c|}{ Saturação (\%) por } & Sat. Al \\
\hline \multicolumn{3}{|c|}{$\mathrm{cmol}_{\mathrm{c}} \mathrm{dm}^{-3}$} & \multicolumn{2}{|c|}{$\%$} & $\begin{array}{c}\mathrm{Ca} / \mathrm{M} \\
\mathrm{g}\end{array}$ & $\mathrm{Ca} / \mathrm{K}$ & $\mathrm{Mg} / \mathrm{K}$ & $\mathrm{Ca}$ & $\mathrm{Mg}$ & K & $\mathrm{H}$ & $\mathrm{m} \%$ \\
\hline \multicolumn{2}{|c|}{0,91} & 4,91 & & 53 & 2,17 & 3,47 & 1,60 & 10,59 & 4,89 & 3,05 & 73,32 & 8,15 \\
\hline
\end{tabular}

Análise realizada no Laboratório Perfil Agroanálise, Sinop-MT, 2012. Fonte: Autores.

Foi realizada gradagem pesada e, de posse das informações da análise de solo, procedeu-se a aplicação e incorporação de calcário dolomítico filler, 60 dias antes do primeiro plantio, em área total, visando à elevação da saturação de bases para $60 \%$, conforme recomendação de Cunha (2003). Logo após, procedeu-se a gradagem niveladora, visando deixar o terreno mais uniforme possível e para incorporação do calcário. Em seguida foi realizada manualmente a demarcação dos blocos, parcelas e covas.

Foram utilizadas mudas do tipo rebento, com peso médio de $180 \mathrm{~g}$, da cultivar Pérola, que passaram por seleção rigorosa, descartando-se mudas indesejáveis, sob o ponto de vista fitossanitário (com resina, sintomas de ocorrência de doenças e pragas). Cada parcela conteve 20 plantas na área total e 10 plantas na área útil. O espaçamento utilizado foi de $1,20 \mathrm{~m}$ entre fileiras, e 0,50 m entre plantas, totalizando 16.666 plantas $\mathrm{ha}^{-1}$.

Durante a condução do ensaio foram realizadas capinas manuais, visando o controle das plantas daninhas. O controle de pragas e doenças durante o desenvolvimento da cultura não foi necessário, pois não houve ocorrência dos mesmos.

Foi instalado sistema de irrigação por aspersão em toda a área, visando o fornecimento de água a partir do início do período seco que ocorreu de maio a setembro. A área experimental era irrigada diariamente, fornecendo água suficiente para suprir a cultura, com média de $150 \mathrm{~mm}$ mensais, conforme recomendado por Cunha (2003).

O delineamento experimental foi o de blocos casualizados no esquema fatorial 3 x 2, com 6 tratamentos, constituídos por 3 doses de potássio $\left(0,60,120 \mathrm{~g}_{\text {planta }^{-1}} \mathrm{de} \mathrm{KCl}\right)$, sendo a quantidade aplicada em todas as plantas em 2 épocas de adubação (após a indução floral: 30 e 60 dias), com 4 repetições.

A adubação nitrogenada (sulfato de amônio) foi realizada em quatro etapas, sendo na ocasião do plantio, 60 dias após o plantio e mais duas adubações após a indução floral (30 e 60 dias), aplicando-se $20 \mathrm{~g}$ planta $^{-1}$. A adubação fosfatada foi realizada no momento do plantio, fornecendo-se $20 \mathrm{~g}$ de superfosfato simples por cova. Para a adubação potássica, as aplicações também foram realizadas após a indução floral, variando de acordo com o intervalo definido (a cada 30 ou 60 dias).

Para a indução floral, foi aplicado $50 \mathrm{~mL} \mathrm{planta}^{-1}$ da solução de Ethrel (0,002\%), aplicando-se na roseta central, às 18 horas, momento em que a temperatura se apresentava mais amena e o céu limpo, sem perspectiva de chuva imediata.

Os frutos, à medida que se formavam, eram embrulhados em papel do tipo kraft, para evitar a queimadura pelo sol. A colheita dos frutos foi realizada quando estes apresentavam, pelo menos, as duas fileiras basais de frutilhos com coloração amarelada típica. Estes eram coletados, contados e pesados em cada área útil das parcelas. Foram avaliadas as seguintes variáveis dos frutos: peso médio do fruto com coroa (PFC) e sem coroa (PFSC), comprimento do fruto (COMP), coloração (COR), formato (FORM) e diâmetro do fruto (DIAM).

Para a determinação do peso dos frutos com e sem coroa, utilizou-se balança eletrônica com precisão de cinco gramas. Para a determinação do comprimento e diâmetro dos eixos dos frutos, as medidas eram realizadas com o auxílio do paquímetro. Para determinação da cor dos frutos foram classificados quanto a sua coloração ou escala de notas que variaram entre 1 e 5, sendo 1 caracterizado como verde intenso e 5 como amarelo intenso, adaptado de Jimenez-Cuesta et al. (1983). 
Para o formato do fruto, estes eram classificados atribuindo-se notas que variaram de 1 (cilíndrico) e 5 (cônico) (adaptado de Sanches \& Lino, 2018).

Após a extração do suco da polpa de cinco frutos escolhidos aleatoriamente de cada parcela, determinou-se a acidez total titulável (ACIDEZ), sendo utilizado um determinador automático de acidez de frutas (Hanna Instruments). Os teores de sólidos solúveis totais ( $\left.{ }^{\circ} \mathrm{BRIX}\right)$ foram determinados nas mesmas amostras, utilizando-se um refratômetro portátil digital (Instrutherm).

Os dados obtidos foram submetidos à análise estatística de variância e as médias comparadas pelo teste de Tukey a 5\% de probabilidade. Para o procedimento estatístico foi utilizado o programa Sisvar (Ferreira, 2014).

\section{Resultados e Discussão}

Avaliando-se as variáveis, observou-se que não houve diferença significativa para FORM e COMP tanto para os fatores isoladamente como sua interação ( $p>0,05$ ). Já para COR e BRIX, a dose do fertilizante influenciou nas médias obtidas $(\mathrm{p}<0,05)$. PFC, PFSC e DIAM foram as variáveis cuja interação entre os fatores foi significativa $(\mathrm{p}<0,05)$. E a acidez foi influenciada apenas pela época de aplicação do fertilizante $(p<0,05)$, conforme apresentado na Tabela 2.

Apesar das variáveis formato (FORM) e comprimento (COMP) de fruto não terem sido influenciadas tanto pela dose como pela época de aplicação do fertilizante potássico, as demais variáveis sofreram sua influência. Algumas características de formação de frutos dificilmente são afetadas por variações na adubação e seu parcelamento, sendo necessário doses significativamente elevadas para que formato e comprimento sofram alterações em frutos de abacaxi. Esse fato se deve a capacidade da espécie em metabolizar e converter os elementos nutritivos captados do ambiente que estão se desenvolvendo em subprodutos, sem acumulá-los de maneira a alterar suas dimensões.

O abacaxi é uma espécie de metabolismo CAM, ou seja, o processamento fisiológico e bioquímico, pela rota do ácido crassuláceo lhe configura tal reação, otimizando o máximo a captura de energia luminosa e sua metabolização.

Tabela 2 - Valores de Q, coeficiente de variação (C.V.) e significância para coloração de fruto (COR), formato do fruto (FORM), peso do fruto com coroa (PFC), peso do fruto sem coroa (PFSC), diâmetro do fruto (DIAM), comprimento do fruto (COMP), teor de açúcares (BRIX) e acidez total titulável (ACIDEZ) em função de épocas de adubação e doses de potássio.

\begin{tabular}{ccccccccc}
\hline FATOR & COR & FORM & PFC & PFSC & DIAM & COMP & BRIX & ACIDEZ \\
\hline ÉPOCA (E) & $0,053 \mathrm{~ns}$ & $0,333 \mathrm{~ns}$ & $0,012 \mathrm{~ns}$ & $0,011 \mathrm{~ns}$ & $0,889^{*}$ & $1,269 \mathrm{~ns}$ & $13,231 \mathrm{~ns}$ & $0,996^{*}$ \\
DOSE (D) & $0,203^{*}$ & $0,332 \mathrm{~ns}$ & $0,036 \mathrm{~ns}$ & $0,025 \mathrm{~ns}$ & $0,430 \mathrm{~ns}$ & $0,736 \mathrm{~ns}$ & $13,990^{*}$ & $0,075 \mathrm{~ns}$ \\
E * D & $0,027 \mathrm{~ns}$ & $0,150 \mathrm{~ns}$ & $0,094^{*}$ & $0,075^{*}$ & $0,836^{*}$ & $3,142 \mathrm{~ns}$ & $5,731 \mathrm{~ns}$ & $0,019 \mathrm{~ns}$ \\
Erro & 0,065 & 0,196 & 0,036 & 0,031 & 0,206 & 1,643 & 10,891 & 0,109 \\
\hline C.V. $(\%)$ & 8,18 & 16,31 & 14,68 & 15,62 & 4,26 & 7,64 & 22,19 & 16,00 \\
\hline
\end{tabular}

Valores seguidos de * indicam significância a 5\% de probabilidade pelo Teste de Tukey. Valores seguidos de ns indicam que não houve diferença estatística entre as médias, pelo teste de Tukey a 5\% de probabilidade. Fonte: Autores.

A coloração dos frutos, apesar de ser uma variável qualitativa, neste estudo, foi convertida em notas, visando melhor elucidar a resposta desses frutos em função do parcelamento na aplicação de adubo potássico. Verificou-se que houve aumento nas médias de coloração indicativa de maturação à medida que as doses de K eram aumentadas (Figura 1). 
Figura 1 - Média de notas para coloração de frutos de abacaxi (escala de notas que variaram entre 1 e 5, sendo 1 caracterizado como verde intenso e 5 como amarelo intenso) em função da adubação potássica.

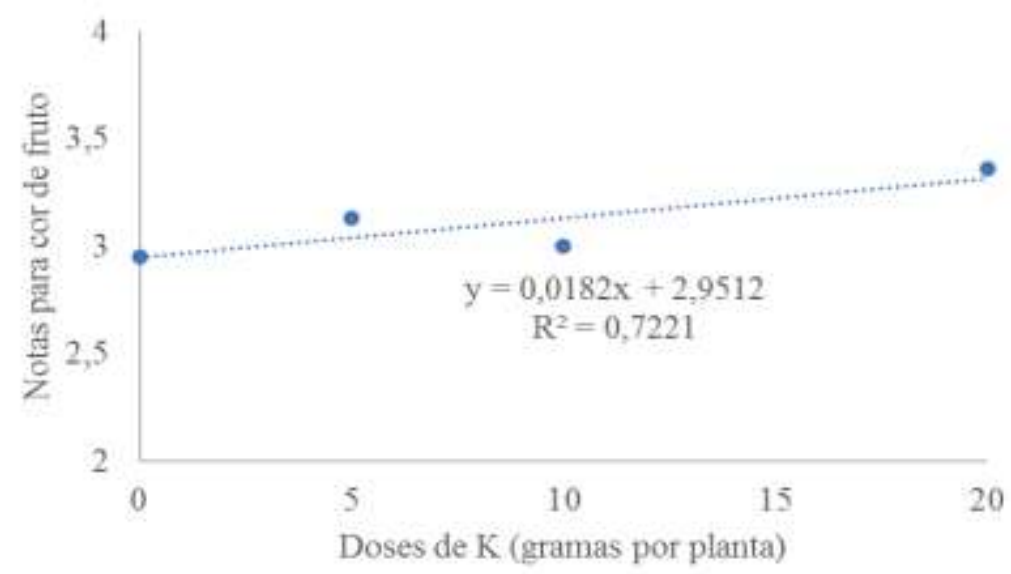

Fonte: Autores.

Esse resultado, referendado por outras variáveis que serão discutidas posteriormente, indicam o efeito do elemento químico na maturação dos frutos do abacaxizeiro. O K é um macroelemento muito importante para o desenvolvimento inicial desta planta e que interfere sobremaneira no resultado final, de interesse econômico, que é seu fruto. Isolado ou em mistura com outros macronutrientes como o nitrogênio e o fósforo, promovem um significativo aumento da absorção ativa pelas suas raízes, promovendo, a partir da hidrólise de ligações de alta energia, como de ATP ou PPi, acumulados na planta em maior quantidade (Fernandes \& Souza, 2006).

Quanto ao peso dos frutos de abacaxi com coroa, em resposta aos fatores submetidos, verificou-se interação entre doses de K e a época de aplicação do fertilizante (Tabela 3). Aos 30 dias, a massa desses frutos aumentou até $10 \mathrm{~g}$ planta ${ }^{-1}$. Na maior dose, houve redução de 25\% em relação à segunda maior dose. Já aos 60 dias, apesar de se verificar incremento numérico nos valores obtidos, não houve diferença estatística, demonstrando que, nas condições experimentais, a aplicação deste fertilizante tardiamente não reflete em resultados significativos, sendo mais adequada a aplicação até os 30 dias do plantio.

Tabela 3 - Peso dos frutos de abacaxi Pérola, com coroa (PFC), em função de épocas de adubação e doses de potássio.

\begin{tabular}{ccc}
\hline \multirow{2}{*}{ Dose de K (g/planta) } & \multicolumn{2}{c}{ Época de aplicação (dias) } \\
\cline { 2 - 3 } 0 & $1,27 \mathrm{~A} \mathrm{a}$ & $1,36 \mathrm{~A} \mathrm{a}$ \\
5 & $1,23 \mathrm{~A} \mathrm{ab}$ & $1,25 \mathrm{~A} \mathrm{a}$ \\
10 & $1,34 \mathrm{~A} \mathrm{ab}$ & $1,36 \mathrm{~A} \mathrm{a}$ \\
20 & $1,10 \mathrm{~B} \mathrm{~b}$ & $1,40 \mathrm{~A} \mathrm{a}$ \\
\hline C.V. $(\%)$ & & 14,68
\end{tabular}

Médias seguidas de mesma letra maiúscula na linha e minúscula na coluna, não diferem entre si pelo teste de Tukey a 5\% de probabilidade. Fonte: Autores.

Em geral a adubação potássica é dividida em duas aplicações, sendo uma no plantio e outra após a indução floral. Essa primeira parcela da adubação permite o aproveitamento deste macronutriente pela muda no início do desenvolvimento e a 
segunda, o uso para características relacionadas à qualidade do fruto. A adubação potássica dessa maneira, em diversos trabalhos, tem demonstrado importante para a qualidade do fruto, especialmente a acidez total titulável e o tamanho do fruto (Cunha et al., 2021; Owureku-Asare et al., 2015; Maeda et al., 2011). Entretanto, neste trabalho, visando melhor aproveitamento do elemento, especialmente na produção do fruto, optou-se pelo parcelamento no florescimento e frutificação, indicando que os melhores resultados podem ser obtidos com $10 \mathrm{~g}^{\text {planta }}{ }^{-1}$ aos 30 dias da indução floral. Esses resultados podem ser referendados quando se compara as adubações nas épocas de aplicação e verifica-se que apenas a maior dosagem de potássio $\left(20 \mathrm{~g} \mathrm{planta}^{-1}\right)$ provocou diferença significativa entre as épocas, havendo incremento de $28 \%$ quando se aplicou $20 \mathrm{~g}$ planta $^{-1}$ aos 60 dias, se comparado com a aplicação aos 30 dias.

Estes resultados, também foram semelhantes aos obtidos quando se retirou a coroa dos frutos e realizou-se a pesagem (Tabela 4). O tamanho e peso das coroas não afetou o resultado das análises, reforçando as observações relatadas anteriormente. Assim, o fruto do abacaxizeiro é que retém o acúmulo e volume de massa obtido a partir dos fatores aos quais for submetido, independentemente da presença da coroa sobre o fruto. Esses ganhos no acúmulo de matéria seca da coroa são importantes porque o peso do fruto é geralmente correlacionado com massa da planta na floração do abacaxi (Hepton, 2003; Teixeira et al., 2011).

Tabela 4 - Peso dos frutos de abacaxi Pérola, sem coroa (PFSC), em função de épocas de adubação e doses de potássio.

\begin{tabular}{ccc}
\hline \multirow{2}{*}{ Dose de K (g/planta) } & \multicolumn{2}{c}{ Época de aplicação (dias) } \\
\cline { 2 - 3 } 0 & $1,05 \mathrm{~A} \mathrm{a}$ & 60 \\
\hline 5 & $1,07 \mathrm{~A} \mathrm{ab}$ & $1,10 \mathrm{~A} \mathrm{a}$ \\
10 & $1,19 \mathrm{~A} \mathrm{ab}$ & $1,09 \mathrm{~A} \mathrm{a}$ \\
20 & $0,87 \mathrm{~B} \mathrm{~b}$ & $1,17 \mathrm{~A} \mathrm{a}$ \\
\hline C.V. $(\%)$ & & $1,24 \mathrm{~A} \mathrm{a}$ \\
\hline
\end{tabular}

Médias seguidas de mesma letra maiúscula na linha e minúscula na coluna, não diferem entre si pelo teste de Tukey a 5\% de probabilidade. Fonte: Autores.

Quanto ao diâmetro dos frutos de abacaxi, também foi verificada interação entre os fatores estudados, ou seja, a interação entre doses de potássio e épocas de aplicação provocação alteração nas médias obtidas para esta variável (Tabela 5). Fica evidente a redução do diâmetro dos frutos à medida que aumentava a dose do elemento aos 30 dias da sua aplicação, sendo que os menores valores obtidos foram verificados nas menores doses. Já aos 60 dias, esse nutriente não afetou essa variável. Assim apenas a aplicação de $20 \mathrm{~g}_{\text {planta }}{ }^{-1}$ de potássio provocou significativa redução do diâmetro dos frutos quando aplicado aos 30 dias após a indução floral. É provável que a reação fisiológica da planta a esta dosagem dessa fonte de potássio tenha sido suficiente para que houvesse essa redução.

De acordo com Teixeira et al. (2011) e Fernandes e Souza (2006), o abacaxi é considerado sensível ao cloro. Assim a reação entre $\mathrm{K}$ e os teores de $\mathrm{Cl}$ nesta formulação podem afetar algumas variáveis na produção de frutos. Estes mesmos autores também sustentam o efeito positivo do potássio e os efeitos prejudiciais do cloro, apesar de que esta é a fonte de potássio mais usada em diversas culturas.

Quanto aos sólidos solúveis totais mensurados nos frutos do abacaxi, verificou-se um incremento desses valores à medida que a dose de potássio era aumentada, seguindo uma resposta linear crescente (Figura 2). O fornecimento desse nutriente promoveu um incremento na concentração desse açúcar, favorecendo a qualidade final do fruto, algo desejado na produção e posterior comercialização. 
Tabela 5 - Diâmetro dos frutos de abacaxi Pérola em função de épocas de adubação e doses de potássio.

\begin{tabular}{ccc}
\hline \multirow{2}{*}{ Dose de K $\left(\mathrm{g}\right.$ planta $\left.^{-1}\right)$} & \multicolumn{2}{c}{ Época de aplicação (dias) } \\
\cline { 2 - 3 } 0 & $11,19 \mathrm{~A} \mathrm{a}$ & $10,82 \mathrm{~A} \mathrm{a}$ \\
5 & $10,76 \mathrm{~A} \mathrm{ab}$ & $10,68 \mathrm{~A} \mathrm{a}$ \\
10 & $10,21 \mathrm{~A} \mathrm{bc}, 94 \mathrm{~A} \mathrm{a}$ & $11,00 \mathrm{~A} \mathrm{a}$ \\
\hline
\end{tabular}

\section{C.V. $(\%)$}

Médias seguidas de mesma letra maiúscula na linha e minúscula na coluna, não diferem entre si pelo teste de Tukey a 5\% de probabilidade. Fonte: Autores.

Estes resultados, em conformidade com a maioria dos estudos que são realizados, avaliando doses crescentes de potássio, eram esperados, dada a íntima relação deste nutriente com o acúmulo de sólidos solúveis totais (Owureku-Asare et al., 2015; Silva et al., 2015; Santos et al., 2017; Cunha et al., 2021).

$\mathrm{O}$ cloreto de potássio é um adubo mineral que têm na sua composição química aproximadamente $60 \%$ de $\mathrm{K}_{2} \mathrm{O}$, sendo responsável pelo transporte da sacarose no floema e, consequentemente, o carregamento dos fotoassimilados na relação fontedreno. Assim, havendo deficiência deste elemento durante o desenvolvimento do fruto, as propriedades morfo-agronômicas como o acúmulo de sólidos solúveis totais podem ser afetadas (Santos et al., 2017).

Figura 2 - Sólidos solúveis totais (BRIX) de frutos de abacaxi em função da adubação potássica.

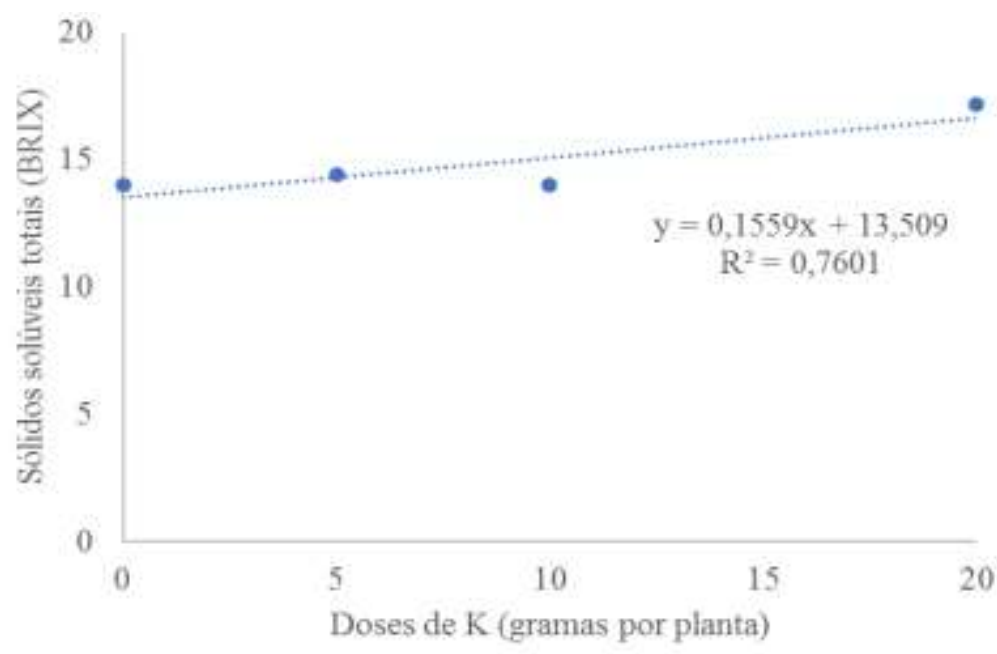

Fonte: Autores.

A acidez total titulável, característica natural da espécie, foi mensurada e, segundo resultados, indicam que essa variável foi 35\% maior quando da adubação aos 30 dias da indução floral (Figura 3). O aumento da acidez dos frutos deve-se à resposta ao fornecimento de fertilização potássica, que acarreta a regulação do transporte no tonoplasto e pode ser um contribuinte essencial para o efeito do Kp na síntese ou armazenamento vacuolar de ácidos orgânicos que aumentam o teor de ácido cítrico dentro da fruta, que é responsável pela acidificação dos compartimentos intracelulares (Botrel et al. 2004; Etienne et al. 2013; Cunha et al., 2021). 
Figura 3 - Acidez total titulável $(\mathrm{pH})$ de frutos de abacaxi em função da época da adubação potássica (em dias).

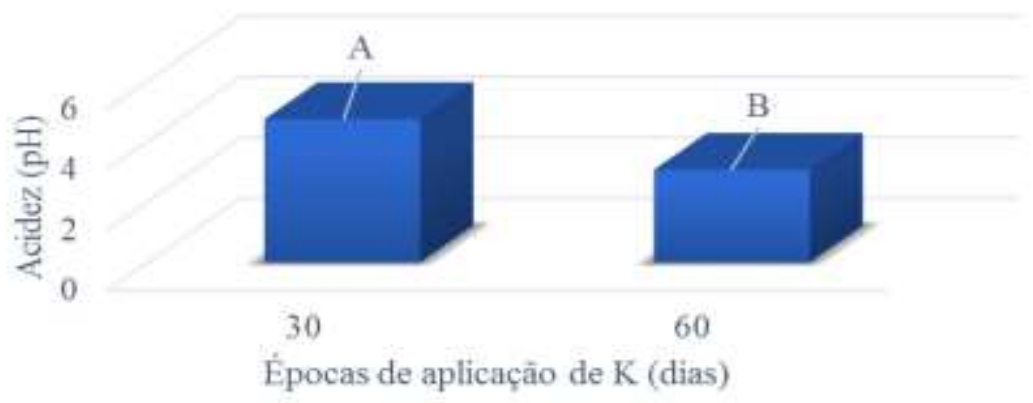

Fonte: Autores.

\section{Conclusão}

Nas condições do presente trabalho, pode-se concluir que: Doses de até 10 gramas por planta de potássio aumentam o peso de frutos, independentemente da presença de coroa nestes; Maiores valores de diâmetro de fruto são obtidos com adubação potássica de até 20 gramas por planta aos 60 dias e até 10 gramas por planta aos 30 dias após a indução floral; O aumento na dose de potássio melhorar coloração de frutos e aumenta o teor de sólidos solúveis destes.

Vale destacar que estes resultados são importantes para os produtores de abacaxi e que futuros estudos que venham a ser realizados possam contemplar maiores doses e mais parcelamentos não só de potássio, mas os demais macronutrientes importantes para o desenvolvimento da planta e formação do fruto.

\section{Agradecimentos}

À FAPEMAT - Fundação de Amparo à Pesquisa de Mato Grosso, pelo aporte financeiro para o desenvolvimento da pesquisa (Edital Universal 005/2012, Projeto 335908/2012).

\section{Referências}

Alvares, C. A., Stape, J. L., Sentelhas, P. C., de Moraes, G., Leonardo, J. \& Sparovek, G. (2014). Köppen's climate classification map for Brazil. Meteorologische Zeitschrift., 6(5), 711-728.

Botrel, N., da Silva, L. F. S., Gomes, A. S. \& Martins, V. M. (2004). Influence of potassium on the susceptiblity internal browing of pinepple (Ananas comosus). Revista Iberoamericana de Tecnologia Postcosecha, 1(6), 17-23.

Conceição, M. A., Yamashita, O. M., Koga, P. S., Peres, W. M., David, G. Q., Teixeira, S. O. \& Carvalho, M. A. C. (2016). Quality and acceptance of pineapple as a result of potassic fertilization. Nativa, 4(6), 368-374.

Cunha, G. A. P. (2003). Abacaxi: manejo cultural e mercado. Frupex.

Cunha, J. M., Freitas, M. S. M., Carvalho, A. C., Caetano, L. C. S., Vieira, M. E., Peçanha, D. A., Lima, T. C., Jesus, A. C. \& Pinto, L. P. (2021). Pineapple yield and fruit quality in response to potassium fertilization. Journal of Plant Nutrition, 44(6), 865-874.

Etienne, A., Genard, M., Lobit, P., Mbeguie-A-Mbeguie, D. \& Bugaud, C. (2013). What controls fleshy fruit acidity? A review of malate and citrate accumulation in fruit cells. Journal of Experimental Botany, 64(6), 1451-1469.

Fernandes, M. S. \& Souza, S. R. (2006). Absorção de nutrientes. In: Fernandes, M. S. (ed). Nutrição mineral de plantas. Viçosa: Sociedade Brasileira de Ciência do Solo.

Ferreira, D. F. (2014). Sisvar: A computer statistical analysis system. Ciência e Agrotecnologia, 35(6), 1039-1042. 
Research, Society and Development, v. 10, n. 7, e42510716722, 2021

(CC BY 4.0) | ISSN 2525-3409 | DOI: http://dx.doi.org/10.33448/rsd-v10i7.16722

Guarçoni, A. M. \& Ventura, J. A. (2011). Adubação N-P-K e o desenvolvimento, produtividade e qualidade dos frutos do abacaxi 'Gold'. Revista Brasileira de Ciência do Solo, 35(12), 1367-1376.

Guimarães, H. A., Rambo, J. R., Laforga, G. \& Santos, P. R. J. (2017). Análise econômica e custo de produção de abacaxi: estudo de caso em Tangará da Serra, Estado de Mato Grosso, 2016. Informações Agronômicas, 47(4), 42-51.

Hepton, A. (2003). Cultural system. In: Bartholomew, DP; Paull, R.E. \& Rohrbach, K.G. (Ed.). Pineapple: botany, production and uses. CABI Publishing.

Jimenez-Cuesta, M., Cuquerella-Cayuela, J., Martinez-Javega, J. M. (1983). Teoria y practica de la desverdizacion de los citricos. INIA.

Kist, B. B., Carvalho, C., Treichel, M. \& Santos, C. E. (2018). Anuário brasileiro da fruticultura. Editora Gazeta Santa Cruz.

Maeda, A. S. (2005). Adubação foliar e axilar na produtividade e qualidade de abacaxi. Dissertação - Mestrado em Sistema de Produção, Universidade Estadual Paulista "Júlio de Mesquita Filho".

Maeda, A. S., Buzetti, S., Boliani, A. C., Benett, C. G. S., Teixeira Filho, M. C. M \& Andreotti, M. (2011). Foliar fertilization on pineapple quality and yield. Pesquisa Agropecuária Tropical, 41(2), 248-253.

Owureku-Asare, M., Agyei-Amponsah, J., Agbemavor, S. W. K., Apatey, J., Sarfo, A. K., Okyere, A. A., Twum, L. A. \& Dodobi, M. T. (2015). Effect of organic fertilizers on physical and chemical quality of sugar loaf pineapple (Ananas comosus L.) grown in two ecological sites in Ghana. African Journal of Food, Agriculture, Nutrition and Development, 15(2), 9982-9995.

Pereira A. S., Shitsuka, D. M., Parreira, F. J., Shitsuka, R. (2018). Metodologia da pesquisa científica. UFSM.

Ribeiro, A. M. A. S. (2016). Parcelamento de nitrogênio e potássio via fertirrigação no cultivo do abacaxizeiro. Dissertação - Mestrado em Agricultura Tropical - Universidade Federal do Espírito Santo.

Sanches, J. \& Lino, A. C. L. (2018). Uso de imagem digital para seleção e classificação de frutas e hortaliças. Informações Tecnológicas IAC. http://www.iac.sp.gov.br/imagem_informacoestecnologicas/90.pdf.

Santos, P. C., Silva, M. P. S. Carvalho, A. J. C., Freitas, M. S. M., Petri, D. J. C., Brochado, R. L. \& Biazatti, M. A. (2017). Pineapple plantlets 'Vitória' fertilized with potassium chloride and silicic acid: growth and nutritional composition, Revista Brasileira de Ciências Agrárias, 12(3), 309-315.

Silva, S. G., Dalbosco, E. Z., Krause, D. P., Krause, W. \& Santi, A. (2015). Fontes de nitrogênio e doses de cloreto de potássio na cultura do abacaxi Pérola. Agrarian Academy, 2(3), 62-70.

Teixeira, L. A. J., Quaggio, J. A., Cantarella, H. \& Mellis, E. V. (2011). Potassium fertilization for pineapple: effects on plant growth and fruit yield. Revista Brasileira de Fruticultura, 33(2), 618-626.

Veloso, C. A. C., Oeiras, A. H. L., Carvalho, E. J. M. \& Souza, F. R. S. (2001). Resposta do abacaxizeiro à adição de nitrogênio, potássio e calcário em Latossolo Amarelo do Nordeste Paraense. Revista Brasileira de Fruticultura, 23(2), 396-402.

Yamashita, O. M., Koga, P. S., Peres, W. M., Carvalho, M. A. C., Campos, O. R., Massaroto, J. A., Roboredo, D., David, G. Q., Arantes, K. R. \& Machado, R. A. F. (2017). Abacaxi - plantio e floração. Cultivar HF, 101(14), 27-29. 